\title{
Mineral Metabolism Management in Hemodialysis Patients with Secondary Hyperparathyroidism in Japan: Baseline Data from the MBD-5D
}

\author{
Masafumi Fukagawa ${ }^{a}$ Hirotaka Komaba $^{a}$ Yoshihiro Onishi ${ }^{\text {b }}$ \\ Shunichi Fukuharac Tadao Akizawad Kiyoshi Kurokawa ${ }^{\mathrm{e}}$ \\ for the MBD-5D Study Group \\ a Division of Nephrology, Endocrinology, and Metabolism, Tokai University School of Medicine, Isehara, \\ ${ }^{b}$ Institute for Health Outcomes and Process Evaluation Research, Kyoto and Tokyo, 'Department of Epidemiology \\ and Healthcare Research, Kyoto University Graduate School of Medicine, Kyoto, dDivision of Nephrology,

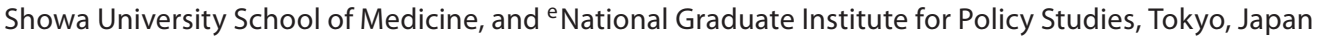

\section{Key Words}

Chronic kidney disease-mineral and bone disorder .

Hemodialysis - Japanese Society for Dialysis

Therapy guideline $\cdot$ Parathyroidectomy $\cdot$ Secondary

hyperparathyroidism

\begin{abstract}
Background/Aims: The Mineral and Bone Disorder Outcomes Study for Japanese CKD Stage 5D Patients (MBD-5D) is a multicenter, prospective observational study of hemodialysis patients with secondary hyperparathyroidism (SHPT) in Japan, where the national guideline recommends targets for serum calcium (8.4-10.0 mg/dl), phosphorus (3.5-6.0 mg/ $\mathrm{dl})$, and intact parathyroid hormone (PTH) (60-180 pg/ml). Methods: The MBD-5D involved patients who were receiving hemodialysis for more than 3 months and met at least one of the following conditions: having intact PTH levels $>180 \mathrm{pg} / \mathrm{ml}$, or receiving intravenous vitamin D receptor activators (VDRAs) or oral VDRA analog. This report describes the baseline characteristics of the study participants and examines factors associated with mineral metabolism control-
\end{abstract}

lability. Results: A total of 8,229 patients were registered from 86 facilities as the whole cohort, and 3,276 patients were randomly selected as the subcohort. The severity of SHPT was associated with a lower likelihood of achieving the targets for calcium and phosphorus, whereas patients with a history of parathyroidectomy were more likely to achieve these targets as compared with those who had not undergone surgery despite high PTH levels. The use of $2.5 \mathrm{mEq} / \mathrm{l}$ calcium dialysate was also associated with a higher likelihood of achieving the targets compared with the use of 3.0 $\mathrm{mEq} / \mathrm{l}$ calcium dialysate. Conclusion: The severity of SHPT and the use of dialysate with higher calcium concentration are associated with practical difficulty in managing mineral metabolism in dialysis patients. Further prospective followup is needed to confirm our findings and to examine their impact on patient-level outcomes.

Copyright $\odot 2011$ S. Karger AG, Basel

Parts of this paper were presented at the XLVII ERA-EDTA Congress in Munich, Germany, June 26, 2010.

\section{KARGER}

Fax +41613061234 E-Mail karger@karger.ch www.karger.com
Prof. Masafumi Fukagawa, MD, PhD, FJSIM, FASN

Division of Nephrology, Endocrinology and Metabolism

Tokai University School of Medicine

143 Shimo-Kasuya, Isehara 259-1193 (Japan)

Tel. +81 46393 1121, ext. 2351, E-Mail fukagawa@ tokai-u.jp 


\section{Introduction}

Chronic kidney disease-mineral and bone disorder (CKD-MBD) is a common complication of dialysis patients, which not only contributes to the development of bone disease [1-3], but also increases the risk for all-cause and cardiovascular mortality [3-8], potentially mediated through vascular calcification $[9,10]$. It is, therefore, crucial to control biochemical parameters of CKD-MBD [e.g., serum calcium, phosphorus, and parathyroid hormone (PTH) levels]. Many national $[11,12]$ and international [13] guidelines recommend control of these parameters within specific target ranges.

Secondary hyperparathyroidism (SHPT), characterized by increased secretion of PTH $[14,15]$, is one of the major abnormalities underlying CKD-MBD. In patients receiving dialysis, SHPT is frequently associated with alterations in calcium and phosphorus metabolism, as a result of either excess PTH alone or the therapeutic use of vitamin D receptor activators (VDRAs) [16]. Generally, SHPT progresses with increasing dialysis vintage, leading to the development of parathyroid hyperplasia. As parathyroid hyperplasia progresses to advanced stages, the expression of calcium-sensing receptors (CaSR) and vitamin $\mathrm{D}$ receptors (VDR) is progressively reduced [1719], resulting in resistance to treatment with VDRAs [2022] and, finally, requiring parathyroidectomy (PTx) [23].

Despite considerable advances in the understanding and management of SHPT, however, mortality rates for patients on maintenance dialysis remain extremely high, with substantial variations between countries. The Dialysis Outcomes and Practice Patterns Study (DOPPS) reported that the crude 1-year mortality rates were $6.6 \%$ in Japan, $15.6 \%$ in Europe, and $21.7 \%$ in the United States [24]. Due to such lower mortality and limited chance for kidney transplantation, a growing number of Japanese patients receive dialysis therapy for a longer time. This could increase the prevalence and degree of SHPT in this population and may differentiate practice patterns for the management of SHPT from that of the rest of the world.

The Japanese Society for Dialysis Therapy (JSDT) guideline, released in 2006, recommends target ranges for serum levels of calcium $(8.4-10.0 \mathrm{mg} / \mathrm{dl})$, phosphorus $(3.5-6.0 \mathrm{mg} / \mathrm{dl})$, and intact PTH $(60-180 \mathrm{pg} / \mathrm{ml})$ [12]. This guideline is characterized by a lower target range for intact PTH compared with that of the KDOQI guidelines $(150-300 \mathrm{pg} / \mathrm{ml}$ ) [11] and the KDIGO guideline (two to nine times the upper limits of normal, corresponding to $130-600 \mathrm{pg} / \mathrm{ml}$ ) [13]. The threshold beyond which surgical PTx is indicated in the JSDT guideline is intact PTH
$>500 \mathrm{pg} / \mathrm{ml}$, which is also lower than that of the KDOQI guidelines (intact PTH $>800 \mathrm{pg} / \mathrm{ml}$ ). The JSDT guideline is, however, mainly based on retrospective analysis of the nationwide survey [7] and expert opinion, due to a paucity of high-level evidence. In addition, cinacalcet hydrochloride $[25,26]$ and lanthanum carbonate $[27,28]$ were launched on the Japanese market after publication of the guideline. These introductions brought about significant changes in the management of CKD-MBD in Japanese dialysis patients.

The Mineral and Bone Disorder Outcomes Study for Japanese CKD Stage 5D Patients (MBD-5D) is a multicenter, prospective observational study of hemodialysis patients with SHPT to examine the impact of patient characteristics and practice patterns on mortality, hospitalization and other clinical outcome measures [29]. This report describes the baseline characteristics of the study participants and examines factors associated with controllability of biochemical variables of CKD-MBD.

\section{Materials and Methods}

\section{Study Design}

The MBD-5D is a 3-year prospective observational study with a case-cohort and a cohort design. Details of the study design have been published [29]. In brief, patients were eligible for inclusion if they had received dialysis regularly for more than 3 months at the participating facilities as of January 1,2008, and if they met at least one of the following conditions: (1) having intact PTH levels $>180 \mathrm{pg} / \mathrm{ml}$, or (2) receiving intravenous VDRAs (calcitriol or maxacalcitol) or oral VDRA analog (falecalcitriol), the only oral drug approved in Japan for the treatment of SHPT. The whole cohort was planned to assess rare clinical events such as all-cause and cardiovascular death, and the subcohort, a random sample (40\%) of the whole cohort, was planned to assess more frequent clinical events and longitudinal laboratory and medication data. The study protocol was approved by central and local ethical review boards. The study was conducted in accordance with the principles of the Declaration of Helsinki, and it was registered at ClinicalTrials.gov, No. NCT00995163.

\section{Data Collection}

Background and demographic information included age, sex, cause of end-stage renal disease (ESRD), dialysis vintage, height, body weight, comorbid conditions, and medical histories. Dialysis prescription, laboratory data, and medication were collected prospectively. Baseline laboratory data, analyzed in local laboratories, were obtained from July 1 to December 31, 2007. Serum levels of calcium, phosphorus, creatinine, hemoglobin, albumin, alkaline phosphatase (ALP), total cholesterol, and C-reactive protein were measured using standard methods. Serum calcium levels were corrected for albumin concentration using Payne's formula [30]. Measurements of intact PTH were performed by various second-generation assays depending on the different participating facilities. Serum whole PTH levels measured with a 
third-generation PTH assay (Whole PTH; Scantibodies Laboratories, Santee, Calif., USA) were converted to intact PTH levels by the following equation: intact PTH $=$ whole PTH $\times 1.7$ [12]. Serum bone-specific ALP (BAP) levels were mostly measured with an enzyme immunoassay kit (Osteolinks BAP; Quidel Corpora Serum, San Diego, Calif., USA), and values measured with other than this assay were not included in the analyses.

\section{Statistical Methods}

Continuous variables were expressed as mean \pm SD and compared with Student $t$ tests or one-way ANOVA (analysis of variance), as appropriate. Categorical variables were expressed as proportions and compared with $\chi^{2}$ test. We used Pearson's correlation analysis to test the association between total ALP and BAP. We used logistic regression to test the association between the achievement of the JSDT targets for calcium and phosphorus and the following factors: severity of SHPT according to the JSDT guideline $(60-180,181-300,301-500$, and $>500 \mathrm{pg} / \mathrm{ml})$, history of successful PTx (defined by having a history of PTx and intact PTH levels $<300 \mathrm{pg} / \mathrm{ml})$, and dialysate calcium use $(2.5$ or $3.0 \mathrm{mEq} / \mathrm{l})$. For each analysis, three types of models were examined: (1) unadjusted models included only the independent variable of interest; (2) case-mix adjusted models included age, sex, dialysis vintage, and cause of ESRD, and (3) multivariable adjusted models included the case-mix covariates plus body mass index (BMI), dialysis adequacy $(\mathrm{Kt} / \mathrm{V})$, history of cardiovascular disease (ischemic heart disease, coronary artery disease, congestive heart failure, cerebrovascular diseases), creatinine, hemoglobin, albumin, total cholesterol, and VDRA use. We also examined the association between the achievement of targets for calcium and phosphorus and the severity of SHPT according to the KDOQI guidelines $(<150,150-300,301-600$, and $>800 \mathrm{pg} / \mathrm{ml})$ and the KDIGO guideline $(<130,130-600$, and $>800 \mathrm{pg} / \mathrm{ml})$. A $10-\mu \mathrm{g}$ dose of maxacalcitol was considered to be equal to $1.5 \mu \mathrm{g}$ of calcitriol, and all results for injectable vitamin D sterol dosages are presented as calcitriol equivalents. $p$ values $\leq 0.05$ were considered as statistically significant. All statistical analyses were performed with SAS software, version 9.1 (SAS Institute, Cary, N.C., USA).

\section{Results}

\section{Overall Demographics}

A total of 8,229 patients from 86 facilities were registered as the whole cohort, and 3,276 patients were randomly selected as the subcohort. There were no significant differences in age, sex, or intact PTH between the whole cohort and subcohort (table 1). Detailed patient characteristics in the subcohort by the JSDT PTH category are shown in table 2 . Mean age was $61.9 \pm 12.7$ years and mean dialysis vintage was $122 \pm 99$ months. The most common primary cause of ESRD was chronic glomerulonephritis. Patients with higher intact PTH levels were associated with longer dialysis vintage and lower proportion of diabetic nephropathy. Similar trends were observed in the analysis using PTH category accor-
Table 1. Baseline characteristics of the whole cohort and the subcohort

\begin{tabular}{llll}
\hline Characteristic & $\begin{array}{l}\text { Whole cohort } \\
(\mathrm{n}=8,229)\end{array}$ & $\begin{array}{l}\text { Subcohort } \\
(\mathrm{n}=3,276)\end{array}$ & $\mathrm{p}$ \\
\hline Age, years & $62.0 \pm 12.6$ & $61.9 \pm 12.7$ & 0.69 \\
Gender female, \% & 37.7 & 38.5 & 0.41 \\
Intact PTH, pg/ml & $341 \pm 272$ & $337 \pm 289$ & 0.43 \\
\hline
\end{tabular}

ding to the KDIGO or KDOQI guidelines (for all online supplementary material, see tables 1 and 2, www. karger.com/doi/10.1159/000327654).

Distributions of serum calcium, phosphorus, intact PTH, and ALP are shown in figure 1. Because the study participants were restricted to those with SHPT, the proportion of patients with intact PTH levels $\leq 180 \mathrm{pg} / \mathrm{ml}$ was substantially lower than that of the general Japanese dialysis population. Serum BAP was measured in 398 patients (12.1\%) as a routine measurement. These levels correlated highly with total ALP levels albeit with wide variations $(r=0.515$; slope $=0.099$; online suppl. fig. 1$)$. Patients with higher intact PTH levels were more likely to have higher BAP levels, suggesting high-turnover bone disease (table 2).

\section{Medication Use}

Among patients in the subcohort, intravenous VDRAs were used in $48.6 \%$ (calcitriol 11.5\%, maxacalcitol 37.3\%) and oral VDRAs were used in $30.6 \%$ (fig. 2). The mean dose of administered intravenous VDRAs, expressed as calcitriol dose equivalents, was $2.14 \pm 1.55 \mu \mathrm{g} /$ week. A distribution of intravenous VDRAs dose is shown in online supplementary figure 2 . Phosphate binders used were calcium carbonate in $43.7 \%$, sevelamer hydrochloride in $18.2 \%$, and both in $23.1 \%$. The proportion of patients treated with intravenous VDRAs and sevelamer hydrochloride tended to be higher and that of calcium carbonate tended to be lower in patients with higher intact PTH levels. All patients with intact PTH levels $\leq 180 \mathrm{pg} / \mathrm{ml} \mathrm{re-}$ ceived an intravenous VDRA or oral VDRA analog falecalcitriol, in accordance to the inclusion criteria. No patients received cinacalcet hydrochloride or lanthanum carbonate, which were not available in Japan at the time of the study start. Dialysates containing 2.5 and $3.0 \mathrm{mEq} / \mathrm{l}$ calcium were used by comparable proportions of patients. Previous history of surgical PTx, percutaneous ethanol injection therapy, and percutaneous vitamin $\mathrm{D}$ injection therapy was noted in $6.2,1.4$, and $1.1 \%$, respectively. 
Table 2. Patient characteristics of the subcohort by the JSDT PTH category

\begin{tabular}{|c|c|c|c|c|c|c|}
\hline Characteristic & $\begin{array}{l}<60 \\
(n=92)\end{array}$ & $\begin{array}{l}60-180 \\
(\mathrm{n}=492)\end{array}$ & $\begin{array}{l}181-300 \\
(\mathrm{n}=1,368)\end{array}$ & $\begin{array}{l}301-500 \\
(n=822)\end{array}$ & $\begin{array}{l}>500 \\
(n=502)\end{array}$ & $\mathrm{p}^{*}$ \\
\hline Age, years & $62.9 \pm 13.9$ & $63.2 \pm 12.5$ & $62.5 \pm 12.7$ & $61.6 \pm 12.9$ & $59.6 \pm 11.8$ & $<0.001$ \\
\hline Gender female, \% & 46.7 & 37.8 & 36.5 & 41.1 & 38.8 & 0.11 \\
\hline \multicolumn{7}{|l|}{ Cause of ESRD, \% } \\
\hline Glomerulonephritis & 46.7 & 43.3 & 40.7 & 45.1 & 58.6 & \multirow[t]{7}{*}{$<0.001$} \\
\hline Diabetic nephropathy & 28.3 & 26.8 & 28.9 & 21.2 & 12.7 & \\
\hline Pyelonephritis & 1.1 & 1.6 & 1.9 & 1.7 & 2.0 & \\
\hline Polycystic kidney disease & 3.3 & 5.1 & 4.1 & 3.9 & 5.4 & \\
\hline Nephrosclerosis & 7.6 & 5.7 & 6.4 & 7.2 & 4.4 & \\
\hline Other & 6.5 & 5.3 & 8.7 & 10.2 & 9.2 & \\
\hline Unknown & 6.5 & 12.2 & 9.3 & 10.7 & 7.8 & \\
\hline Dialysis vintage, months & $110 \pm 110$ & $112 \pm 98$ & $110 \pm 96$ & $125 \pm 94$ & $160 \pm 103$ & $<0.001$ \\
\hline History of CVD, \% & 40.2 & 45.3 & 44.3 & 41.6 & 40.6 & 0.39 \\
\hline BMI & $20.8 \pm 4.2$ & $21.2 \pm 3.3$ & $21.4 \pm 3.5$ & $21.5 \pm 3.9$ & $21.2 \pm 3.4$ & 0.39 \\
\hline $\mathrm{Kt} / \mathrm{V}$ & $1.4 \pm 0.3$ & $1.4 \pm 0.3$ & $1.4 \pm 0.3$ & $1.4 \pm 0.3$ & $1.4 \pm 0.3$ & 0.100 \\
\hline \multicolumn{7}{|l|}{ Laboratory data } \\
\hline Calcium, mg/dl & $10.1 \pm 1.1$ & $9.6 \pm 0.8$ & $9.3 \pm 0.9$ & $9.5 \pm 3.4$ & $9.7 \pm 0.9$ & $<0.001$ \\
\hline Phosphorus, mg/dl & $4.9 \pm 1.4$ & $5.2 \pm 1.3$ & $5.3 \pm 1.3$ & $5.8 \pm 1.4$ & $6.1 \pm 1.5$ & $<0.001$ \\
\hline Intact PTH, pg/ml & $34 \pm 15$ & $125 \pm 34$ & $234 \pm 35$ & $380 \pm 55$ & $807 \pm 470$ & $<0.001$ \\
\hline ALP, U/l & $276 \pm 216$ & $242 \pm 109$ & $266 \pm 136$ & $294 \pm 133$ & $372 \pm 259$ & $<0.001$ \\
\hline $\mathrm{BAP}, \mathrm{U} / \mathrm{l}$ & $19.4 \pm 6.3$ & $25.7 \pm 14.9$ & $34.1 \pm 31.3$ & $46.5 \pm 41.9$ & $58.6 \pm 59.5$ & $<0.001$ \\
\hline Creatinine, mg/dl & $10.2 \pm 2.9$ & $11.1 \pm 2.8$ & $11.1 \pm 2.9$ & $11.2 \pm 2.8$ & $11.8 \pm 2.8$ & $<0.001$ \\
\hline Hemoglobin, g/dl & $10.3 \pm 1.2$ & $10.9 \pm 5.6$ & $10.5 \pm 1.3$ & $10.5 \pm 1.1$ & $10.5 \pm 1.2$ & 0.020 \\
\hline Albumin, g/dl & $3.6 \pm 0.6$ & $3.8 \pm 0.4$ & $3.7 \pm 0.4$ & $3.8 \pm 0.4$ & $3.8 \pm 0.4$ & $<0.001$ \\
\hline Total cholesterol, mg/dl & $155 \pm 38$ & $154 \pm 35$ & $155 \pm 37$ & $155 \pm 46$ & $153 \pm 33$ & 0.93 \\
\hline C-reactive protein, $\mathrm{mg} / \mathrm{dl}$ & $0.7 \pm 1.8$ & $0.5 \pm 1.2$ & $0.4 \pm 1.3$ & $0.5 \pm 1.2$ & $0.5 \pm 2.2$ & 0.66 \\
\hline IV vitamin D use, $\%$ & 64.1 & 75.2 & 33.8 & 45.1 & 65.9 & $<0.001$ \\
\hline Calcitriol, \% & 16.9 & 27.6 & 24.9 & 20.8 & 22.4 & 0.14 \\
\hline Maxacalcitol, \% & 83.1 & 73.0 & 75.8 & 79.2 & 77.9 & 0.19 \\
\hline IV vitamin $\mathrm{D}$ dose, $\mu \mathrm{g} /$ week $^{1}$ & $1.90 \pm 1.20$ & $1.95 \pm 1.16$ & $2.10 \pm 1.47$ & $2.12 \pm 1.68$ & $2.47 \pm 1.86$ & $<0.001$ \\
\hline Oral vitamin $\mathrm{D}$ use, $\%$ & 41.3 & 24.4 & 39.8 & 28.5 & 13.1 & $<0.001$ \\
\hline Falecalcitriol, $\%$ & 50.0 & 60.0 & 14.3 & 16.7 & 21.2 & $<0.001$ \\
\hline Calcitriol, \% & 28.9 & 12.5 & 24.6 & 28.2 & 21.2 & 0.018 \\
\hline Alfacalcidol, \% & 21.1 & 27.5 & 61.6 & 55.6 & 57.6 & $<0.001$ \\
\hline Phosphate binder use, $\%$ & 83.7 & 88.6 & 83.7 & 84.8 & 87.3 & 0.061 \\
\hline Calcium carbonate, $\%$ & 73.9 & 74.2 & 70.0 & 64.6 & 53.4 & $<0.001$ \\
\hline Sevelamer hydrochloride, \% & 27.2 & 37.6 & 36.8 & 42.9 & 56.8 & $<0.001$ \\
\hline Dialysate calcium, mEq/l & $2.8 \pm 0.2$ & $2.7 \pm 0.2$ & $2.8 \pm 0.2$ & $2.8 \pm 0.3$ & $2.8 \pm 0.3$ & 0.19 \\
\hline $2.5 \mathrm{mEq} / 1, \%$ & 40.7 & 50.2 & 44.7 & 42.3 & 44.8 & 0.23 \\
\hline $3.0 \mathrm{mEq} / \mathrm{l}, \%$ & 52.7 & 44.7 & 47.2 & 48.5 & 46.2 & \\
\hline Other, \% & 6.6 & 5.1 & 8.1 & 9.3 & 9.0 & \\
\hline History of PTx, \% & 11.1 & 3.3 & 5.1 & 6.6 & 10.5 & $<0.001$ \\
\hline History of PEIT, \% & 1.1 & 0.7 & 0.8 & 1.8 & 3.2 & 0.001 \\
\hline History of PDIT, \% & 0.0 & 0.9 & 0.7 & 1.4 & 1.9 & 0.15 \\
\hline
\end{tabular}

$\mathrm{ALP}=$ Alkaline phosphatase; $\mathrm{BAP}=$ bone-specific alkaline phosphatase; $\mathrm{BMI}=$ body mass index; $\mathrm{CVD}=$ cardiovascular disease; ESRD = end-stage renal disease; IV = intravenous; JSDT = Japanese Society for Dialysis Therapy; PDIT = percutaneous vitamin D injection therapy; PEIT = percutaneous ethanol injection therapy; $\mathrm{PTH}=$ parathyroid hormone; $\mathrm{PTx}=$ parathyroidectomy.

${ }^{*} \mathrm{p}$ value refers to overall ANOVA or $\chi^{2}$ analysis. ${ }^{1}$ Vitamin D doses were calcitriol dose equivalents. $1.5 \mu \mathrm{g}$ of calcitriol $=10 \mu \mathrm{g}$ of maxacalcitol. 


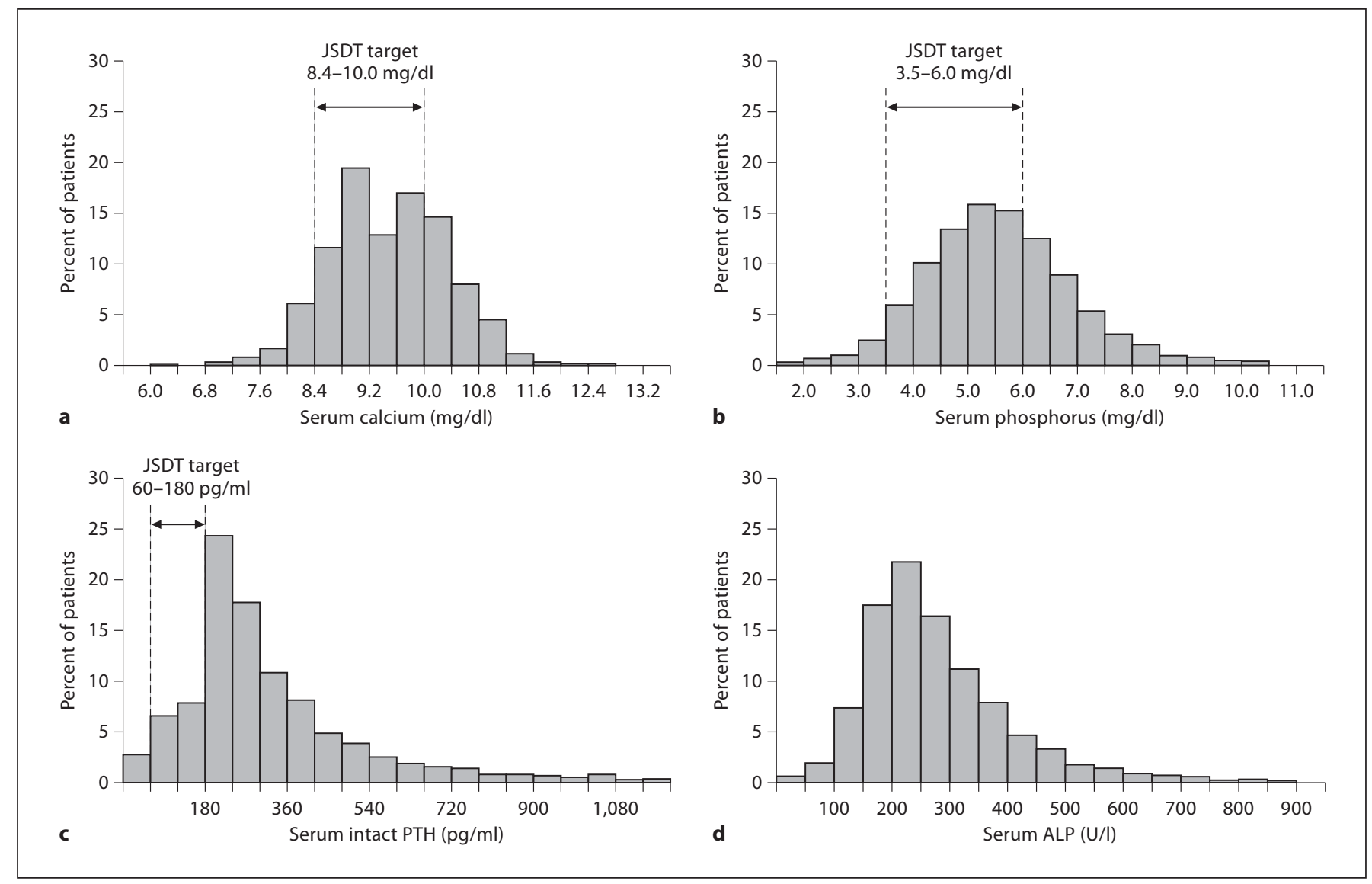

Fig. 1. Distributions of serum calcium (a), phosphorus (b), intact PTH (c), and ALP (d) among the study population. The vertical dashed lines indicate the target ranges for each biochemical parameters specified in the JSDT guideline.

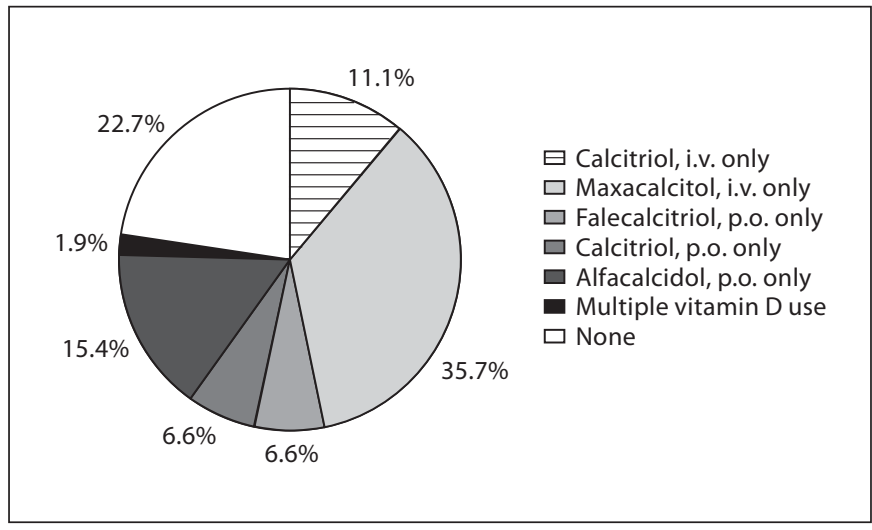

Fig. 2. Proportion of patients treated with different VDRAs.

\section{Severity of SHPT and Mineral Metabolism Management}

The proportions of patients achieving the JSDT targets for serum calcium (8.4-10.0 mg/dl) and phosphorus (3.5$6.0 \mathrm{mg} / \mathrm{dl}$ ) were 64.7 and $62.7 \%$, respectively, and $40.9 \%$ of patients achieved both targets simultaneously (table 3 ). The proportions of patients achieving both the serum calcium and phosphorus targets were $47.8 \%$ for those with intact PTH $60-180 \mathrm{pg} / \mathrm{ml}, 48.3 \%$ for those with intact PTH $181-300 \mathrm{pg} / \mathrm{ml}, 35.2 \%$ for those with intact PTH $301-500 \mathrm{pg} / \mathrm{ml}$, and $25.0 \%$ for those with intact PTH $>500 \mathrm{pg} / \mathrm{ml}(\mathrm{p}<0.001)$. In a subgroup analysis that excluded patients receiving VDRAs, the corresponding percentages were $46.3 \%$ for those with intact PTH 181$300 \mathrm{pg} / \mathrm{ml}, 37.4 \%$ for those with intact PTH 301-500 pg/ $\mathrm{ml}$, and $30.9 \%$ for those with intact PTH $>500 \mathrm{pg} / \mathrm{ml}$ $(\mathrm{p}=0.007)$. Logistic regression analysis showed that severe SHPT was associated with a lower likelihood of 
Table 3. Proportion of patients in each group classified by the JSDT targets for serum calcium and phosphorus

\begin{tabular}{llrr}
\hline Calcium, mg/dl & \multicolumn{3}{l}{ Phosphorus, $\mathrm{mg} / \mathrm{dl}$} \\
\cline { 2 - 4 } & $<3.5$ & $3.5-6.0$ & $>6.0$ \\
\hline$<8.4$ & $0.6 \%$ & $5.8 \%$ & $3.1 \%$ \\
$8.4-10.0$ & $3.0 \%$ & $40.9 \%$ & $20.8 \%$ \\
$>10.0$ & $0.9 \%$ & $15.9 \%$ & $8.9 \%$ \\
\hline
\end{tabular}

Table 4. Characteristics of the subgroup by dialysate calcium*

\begin{tabular}{lllc}
\hline Characteristic & $\begin{array}{l}2.5 \mathrm{mEq} / \mathrm{l} \\
(\mathrm{n}=1,467)\end{array}$ & $\begin{array}{l}3.0 \mathrm{mEq} / \mathrm{l} \\
(\mathrm{n}=1,543)\end{array}$ & $\mathrm{p}$ \\
\hline Age, years & $62.4 \pm 12.8$ & $61.8 \pm 12.7$ & 0.15 \\
Gender female, \% & 39.5 & 37.7 & 0.31 \\
Dialysis vintage, months & $113 \pm 95$ & $128 \pm 101$ & $<0.001$ \\
Laboratory data & & & \\
$\quad$ Calcium, mg/dl & $9.4 \pm 0.9$ & $9.6 \pm 2.6$ & $<0.001$ \\
$\quad$ Phosphorus, mg/dl & $5.5 \pm 1.4$ & $5.5 \pm 1.4$ & 0.96 \\
$\quad$ Intact PTH, pg/ml & $340 \pm 284$ & $332 \pm 305$ & 0.46 \\
$\quad$ ALP, U/l & $290 \pm 180$ & $284 \pm 153$ & 0.41 \\
$\quad$ BAP, U/1 & $39.0 \pm 32.3$ & $34.2 \pm 43.5$ & 0.27 \\
IV vitamin D use, \% & 48.7 & 47.6 & 0.55 \\
$\quad$ Calcitriol, \% & 19.0 & 28.9 & $<0.001$ \\
$\quad$ Maxacalcitol, \% & 81.5 & 71.4 & $<0.001$ \\
IV vitamin D dose, $\mu$ g/week & $2.37 \pm 1.67$ & $1.94 \pm 1.46$ & $<0.001$ \\
Oral vitamin D use, \% & 32.4 & 29.4 & 0.079 \\
$\quad$ Falecalcitriol, \% & 15.4 & 31.7 & $<0.001$ \\
$\quad$ Calcitriol, \% & 30.1 & 18.3 & $<0.001$ \\
$\quad$ Alfacalcidol, \% & 54.7 & 50.7 & 0.21 \\
Phosphate binder use, \% & 85.7 & 84.5 & 0.37 \\
$\quad$ Calcium carbonate, \% & 69.4 & 64.9 & 0.008 \\
$\quad$ Sevelamer hydrochloride, \% & 41.3 & 39.9 & 0.42 \\
History of PTx, \% & 5.7 & 6.2 & 0.55 \\
History of PEIT, \% & 1.7 & 1.3 & 0.33 \\
History of PDIT, \% & 0.6 & 1.4 & 0.042 \\
\hline
\end{tabular}

* Patients not treated with dialysate calcium of 2.5 or $3.0 \mathrm{mEq} / 1$ were excluded in the analysis.

** Calcitriol dose equivalents. $1.5 \mu \mathrm{g}$ of calcitriol $=10 \mu \mathrm{g}$ of maxacalcitol.

ALP $=$ Alkaline phosphatase; BAP = bone-specific alkaline phosphatase; IV = intravenous; PDIT = percutaneous vitamin D injection therapy; PEIT = percutaneous ethanol injection therapy; $\mathrm{PTH}=$ parathyroid hormone; $\mathrm{PTx}=$ parathyroidectomy.

achieving the JSDT targets for serum calcium and phosphorus in crude, case-mix adjusted and fully adjusted models (fig. 3). The results were unchanged in analyses that used the KDIGO or KDOQI PTH category (online suppl. fig. 3, 4).

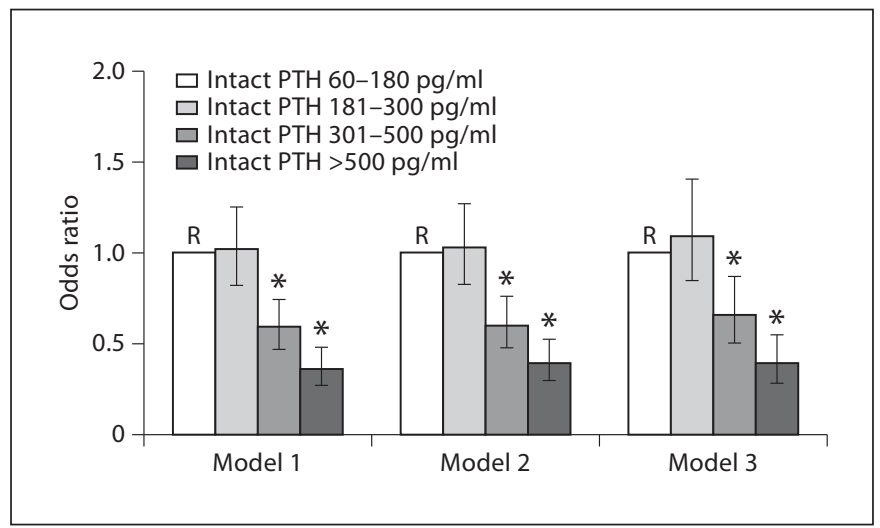

Fig. 3. Odds ratios for achieving the target ranges for serum calcium and phosphorus according to the JSDT PTH category. Model 1: unadjusted; Model 2: adjusted for age, sex, dialysis vintage, and cause of ESRD; Model 3: adjusted for covariates in Model 2 plus BMI, dialysis adequacy $(\mathrm{Kt} / \mathrm{V})$, history of cardiovascular disease, creatinine, hemoglobin, albumin, total cholesterol, and VDRA use. ${ }^{*} \mathrm{p}<0.05 . \mathrm{R}=$ Reference.

History of PTx and Mineral Metabolism Management

Compared with patients who had not undergone surgical PTx despite high PTH levels (>500 pg/ml), a greater proportion of patients with a history of successful PTx achieved the targets for serum calcium and phosphorus simultaneously ( 25.5 and $38.6 \%$, respectively; $\mathrm{p}=0.013$ ). Logistic regression analysis showed that a history of successful PTx was associated with a higher likelihood of achieving the targets for serum calcium and phosphorus in all analysis models (fig. 4). These results were materially unchanged when the threshold for surgical PTx specified in the KDOQI guidelines (intact PTH $>800 \mathrm{pg} / \mathrm{ml}$ ) was applied (data not shown).

\section{Dialysate Calcium Concentration and Practice \\ Patterns of CKD-MBD}

Patient characteristics according to the dialysate calcium concentration, 2.5 or $3.0 \mathrm{mEq} / \mathrm{l}$, are shown in table 4 . Serum calcium levels were significantly lower in patients using $2.5 \mathrm{mEq} / \mathrm{l}$ calcium dialysate, whereas intact PTH and phosphorus levels were comparable between patients on 2.5 calcium dialysate and those on 3.0 $\mathrm{mEq} / \mathrm{l}$ calcium dialysate. The use of $2.5 \mathrm{mEq} / \mathrm{l}$ calcium dialysate was associated with increased use of calcium carbonate and high doses of intravenous VDRAs. The proportion of patients receiving sevelamer hydrochloride was comparable between groups.

Both serum calcium and phosphorus levels were within the target ranges in $43.4 \%$ of patients using $2.5 \mathrm{mEq} / 1$ 


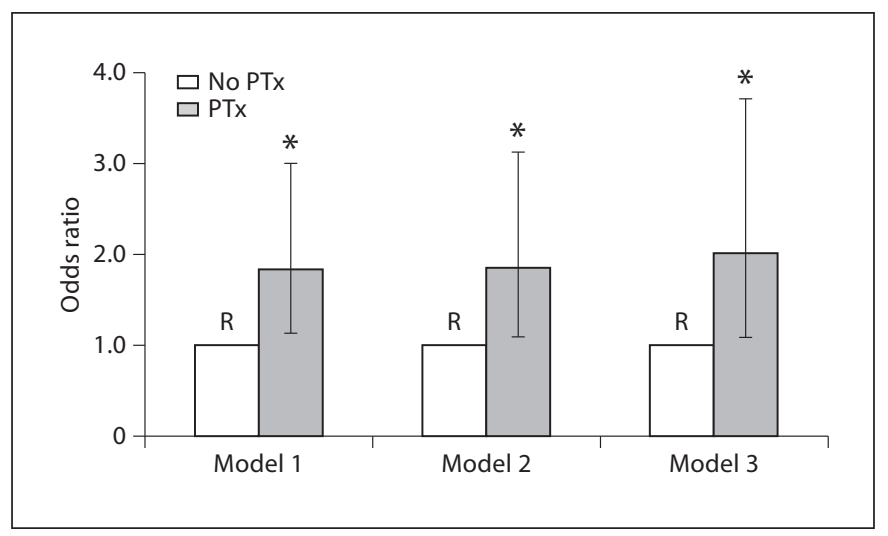

Fig. 4. Odds ratios for achieving the target ranges for serum calcium and phosphorus according to a history of parathyroidectomy. Model 1: unadjusted; Model 2: adjusted for age, sex, dialysis vintage, and cause of ESRD; Model 3: adjusted for covariates in Model 2 plus BMI, dialysis adequacy (Kt/V), history of cardiovascular disease, creatinine, hemoglobin, albumin, total cholesterol, and VDRA use. ${ }^{*} \mathrm{p}<0.05$. $\mathrm{R}=$ Reference.

calcium dialysate and $38.7 \%$ of patients using $3.0 \mathrm{mEq} / \mathrm{l}$ calcium dialysate $(\mathrm{p}=0.010)$. Logistic regression analysis showed that the use of $2.5 \mathrm{mEq} / \mathrm{l}$ calcium dialysate was associated with a higher likelihood of achieving the JSDT targets for serum calcium and phosphorus in all analysis models (fig. 5).

\section{Discussion}

The MBD-5D is a multicenter, prospective observational study among hemodialysis patients with SHPT in Japan [29]. This paper describes the baseline characteristics of patients participating in the study. The results revealed that the proportion of patients who achieved the JSDT targets for serum calcium and phosphorus still remains low, particularly in patients with higher PTH levels. Progression of SHPT was independently associated with increased difficulty in controlling serum calcium and phosphorus, whereas a history of PTx for severe SHPT was associated with improved control of these variables. It was also found that as compared with 3.0 $\mathrm{mEq} / \mathrm{l}$ calcium dialysate, the use of $2.5 \mathrm{mEq} / \mathrm{l}$ calcium dialysate was associated with enhanced use of calcium carbonate and intravenous VDRAs, and related to increased proportion of patients achieving the targets for serum calcium and phosphorus.

It is well known that the development of SHPT, characterized by elevated PTH secretion, contributes to in-

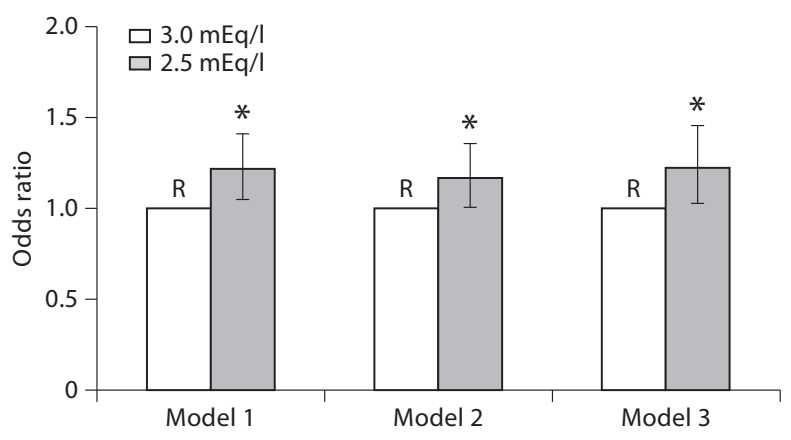

Fig. 5. Odds ratios for achieving the target ranges for serum calcium and phosphorus according to the dialysate calcium use. Model 1: unadjusted; Model 2: adjusted for age, sex, dialysis vintage, and cause of ESRD; Model 3: adjusted for covariates in Model 2 plus BMI, dialysis adequacy (Kt/V), history of cardiovascular disease, creatinine, hemoglobin, albumin, total cholesterol, and VDRA use. ${ }^{*} \mathrm{p}<0.05$. $\mathrm{R}=$ Reference.

creased risk for bone fractures [1-3] and cardiovascular diseases [3-8]. Previous studies showed that high PTH damages cardiac myocytes [31] and contributes to the development of uremic cardiomyopathy [32]. However, recent works suggest that elevations in serum calcium and phosphorus that accompany SHPT play a more critical role in the development of vascular calcification rather than PTH itself $[9,10]$. Analyses from several large dialysis databases provide support for this notion, demonstrating that serum calcium and phosphorus levels are more closely associated with all-cause and cardiovascular mortality risks than PTH levels are [3-8]. Based on these data, many guidelines released in recent years recommend giving priority to the control of serum calcium and phosphorus rather than PTH levels [11-13].

In this regard, our findings that progression of SHPT is associated with increased difficulty in managing serum calcium and phosphorus are worthy of consideration. This suggests that halting progression of SHPT is crucial to adequately control serum calcium and phosphorus and thereby improve survival, even though PTH has only a limited independent effect on outcomes as reported in previous observational studies [3-8]. In this study, we also found an association between a history of successful PTx and improved control of serum calcium and phosphorus, which further bolsters the hypothesis that the degree of SHPT has a considerable impact on the management of mineral metabolism. Recent observational data suggest that PTx for severe SHPT improves 
survival at least in the long term [33]; these positive effects by PTx on survival may be attributed to improved control of serum calcium and phosphorus after the surgery, as well as marked reduction in PTH levels.

Abnormalities in calcium and phosphorus metabolism in SHPT are not only caused by high PTH levels, but also by therapeutic measures used to manage it. VDRAs enhance the intestinal absorption of calcium and phosphorus, and their use to manage SHPT raises serum calcium and phosphorus levels [16]. In this study, we showed that the development and progression of SHPT is associated with practical difficulty in managing serum calcium and phosphorus, and notably, this was also the case with patients who were not treated with VDRAs. This finding suggests that SHPT causes abnormal mineral metabolism independently of the effects of VDRAs, presumably by directly affecting bone to increase calcium and phosphate efflux.

This study also showed that dialysate calcium concentration, 2.5 or $3.0 \mathrm{mEq} / \mathrm{l}$, affect the practice patterns and controllability of mineral metabolism in CKD-MBD. Compared with $3.0 \mathrm{mEq} / \mathrm{l}$ calcium dialysate, the use of $2.5 \mathrm{mEq} / \mathrm{l}$ calcium dialysate was associated with increased use of calcium carbonate and high doses of VDRAs, while improving achievement of the JSDT targets for serum calcium and phosphorus. Theoretically, it is possible that the use of $2.5 \mathrm{mEq} / \mathrm{l}$ calcium dialysate resulted in a tendency towards lower serum calcium compared with $3.0 \mathrm{mEq} / \mathrm{l}$ calcium dialysate, which may have enabled the administration of calcium carbonate, leading to improved management of serum phosphorus. Possibly for the same reason, the doses of VDRAs might have been increased in patients on $2.5 \mathrm{mEq} / \mathrm{l}$ calcium dialysate compared with those on $3.0 \mathrm{mEq} / \mathrm{l}$ calcium dialysate [34]. Recent retrospective data suggest a possible link between the use of VDRAs and improved survival [35-37]. Whether the increased use of VDRAs as well as improved management of mineral metabolism associated with the use of 2.5 calcium dialysate provides a survival benefit, or, rather, higher dose of VDRAs and calcium-based binders limit the survival advantage predicted by a better biochemical control should be investigated in future studies.

In this study, we also examined baseline serum ALP levels among patients in the MBD-5D, showing that $22.9 \%$ of patients had serum ALP $>350 \mathrm{U} / 1$ (approximately the upper limit of the reference ranges). It is well known that serum ALP can be used as a biochemical marker of high-turnover bone disease [38]. In addition, recent epidemiological studies have shown an increased risk of allcause and cardiovascular mortality associated with high- er serum ALP in hemodialysis patients [39, 40]. It is also reported that higher serum ALP was associated with coronary artery calcification in hemodialysis patients [41]. Although definitive evidence remains to be provided, these data lead to the hypothesis that serum ALP could be a potential biomarker to guide treatment of CKDMBD. The MBD-5D will determine whether lower serum ALP is also associated with better survival in Japanese hemodialysis patients.

Our study has several important limitations. First, this was a baseline analysis of a prospective cohort study, and the cross-sectional nature of the study does not allow us to determine the causal direction between the severity of SHPT and difficulty in managing mineral metabolism. Thus, although we used rigorous statistical methods to adjust for baseline differences between patients, we cannot exclude the possibility that poor control of mineral metabolism contributes to the development of SHPT. Second, all study participants in this study were Japanese patients and their SHPT were mostly treated according to the JSDT guideline. We do not, however, consider that our results should be limited to Japanese patients. In Japan, laboratory measurements are usually performed following the longest interdialytic period; thus, the slightly higher target range for serum phosphorus in the JSDT guideline can be considered to be identical to that of the KDOQI guidelines [42]. Also, the upper limit of the target range for serum calcium in the JSDT guideline is slightly higher than that of the KDOQI guidelines; however, recent clinical data suggest that serum calcium in this range is associated with lowest mortality in the US population [43]. Finally, and most importantly, the target range for intact PTH in the JSDT guideline is substantially lower than that of the KDOQI and the KDIGO guideline. Although, whether such a lower target for intact PTH actually provides a survival benefit remains to be determined, our sensitivity analysis showed that the use of PTH category according to the KDIGO or KDOQI guidelines did not alter the association between the severity of SHPT and mineral metabolism management. Collectively, the results of this study would provide important implications for the management of SHPT worldwide, although our findings should be confirmed by international studies, such as the DOPPS and the Current Management of Secondary Hyperparathyroidism: A Multicenter Observational Study (COSMOS) [44].

In conclusion, this baseline analysis of the MBD-5D suggests that the severity of SHPT is associated with practical difficulty in managing mineral metabolism in CKD and that PTx for advanced SHPT leads to improved con- 
trol of serum calcium and phosphorus. Dialysate calcium concentration also appears to substantially affect practice patterns for CKD-MBD and controllability of mineral metabolism. Further prospective investigation will determine associations between practice patterns for CKDMBD and improved patient-level outcomes in Japan, which will provide important perspectives for future clinical trials and clinical practice guidelines worldwide.

\section{Appendix}

The following investigators also participated in this study, Nobuo Hashimoto (H·N.MEDIC), Mari Ishida (Kitasaito Hospital), Toshiyuki Date (Date Clinic), Kiyotaka Yabuki (Yabuki Hospital), Hideki Tanida (Tendo Onsen Yabuki Clinic), Fumitoshi Yamauchi (San-ai Hospital), Mikihiko Fujishima (Yahaba Clinic), Tomohito Matsunaga (Eijinkai Hospital), Jun Urae (Ishinomaki Clinic), Hiroshi Kawaguchi (Iwaki Urological Hospital), Ikuo Takahashi (Kisen Hospital), Yoshiko Tanaka (Shinjuku-Koshin Clinic), Hideo Kobayashi (Suda Clinic), Maki Takahashi (Suda Naika Clinic), Tatsuya Nonaka (Seishokai Memorial Hospital), Hideto Emoto (Tokai Hospital), Kyosuke Nishio (Shinkoiwa Clinic), Atsushi Hayama (Moriyama Rehabilitation Hospital), Toshio Shinoda (Kawakita General Hospital Dialysis Center), Takashi Kono (Mihama Narita Clinic), Takahiro Mochizuki (Kameda Medical Center), Yasuo Kimura (Shin-kashiwa Clinic), Noriyoshi Murotani (Chiba Social Insurance Hospital), Satoshi Yamaguchi (Asahi Hospital), Taichi Nakanishi (Kurihama Clinic), Kiyoshi Ozawa (Yokosuka Clinic), Takashi Nagaoka (Sagamihara Clinic), Takao Suga (Bousei Hiratsuka Clinic), Masakazu Suda (Suda Medical Clinic), Yoshikazu Goto (Saiyu Soka Hospital), Michio Kuwahara (Shuwa General Hospital Hemodialysis Clinic), Hiromi Shimoyama (Yuai Clinic), Kimihiko Matsuyama (Misato Kenwa Clinic), Kazue Ueki (Toho Hospital), Kyoko Ito (Heisei Hidaka Clinic), Katsuhiko Miyamoto (Seseragi Hospital), Takashi Ishizu (Tukuba Central Hospital), Shuichi Kikuchi (Ohba Renal Clinic), Masaki Kobayashi (Tokyo Medical University Ibaraki Medical Center), Mitsuyoshi Furuhashi (Maruyama Hospital), Masanori Wakabayashi (Bousei Dai-ichi Clinic), Kazuyoshi Nakamura (Fujidaiichi Clinic), Hirotake Kasuga (Kaikoukai Central Clinic), Itsuo Yokoyama (Nagoya Memorial Foundation Narumi Clinic), Chikao Yamazaki (Masuko Clinic SUBARU), Kijun Nagata (Sawada Hospital), Yasumasa Kawade (Suzuka Kidney Clinic), Toshiaki Kawanaka (Ishikiriseiki Hospital), Yoshihiro Tsujimoto (Inoue Hospital), Mikio Okamura (Ohno Memorial Hospital), Shigeki Okada (Okada Clinic), Senji Okuno (Kidney Center Shirasagi Clinic), Harumi Nagayama (Nagayama Hemodialysis Clinic), Shuji Okazaki (Nagayama Hospital), Yoshinori Tone (Fujii Clinic), Ibuki Yajima (Ibuki Clinic), Kouji Shibuya (Sumiyoshigawa Hospital), Kunihiko Yoshiya (Hara Genitourinary Hospital), Morihiro Kondou (Otowa Kinen Hospital), Satoru Yamazaki (Tojinkai Hospital), Ryoichi Miyazaki (Fujita Memorial Hospital), Katsuhiko Arimoto (Shigei Medical Research Hospital), Misaki Moriishi (Nakajima Tsuchiya Clinic), Takahito Nasu (Tokuyama Central Hospital), Seiichi Obayashi (Kinashi Obayashi Hospital), Yuzuru Sato (Sato Junkankika Naika), Takao Tanaka (Ohji Hospital), Hidetoshi Nakamura (Kokura
Daiichi Hospital), Nobuhiko Koga (Shin-Koga Clinic), Harumichi Higashi (St. Mary’s Hospital), Kougi Yuu (Takahashi Naika Clinic), Asako Kitamura (Chikuho Social Insurance Hospital), Tomoji Matsumae (Murakami Memorial Hospital), Katsushige Abe (Jinikai Hospital), Masahiro Kawatomi (Kawatomi Internal Medicine Clinic), Motoko Tanaka (Akebono Clinic), Chisa Nogami (Kumamoto Urological Hospital), Etsuo Yoshidome (Ikeda Hospital), Shinyu Miyagi (Okinawa Daiichi Hospital), Satoshi Nakazato (Chibana Clinic), Yoshiki Shiohira (Tomishiro Central Hospital), and Kiyoyuki Tokuyama (Tokuyama Clinic).

\section{Acknowledgements}

We would like to thank the MBD-5D study advisory investigators, Masashi Suzuki (Shinrakuen Hospital), Yoshindo Kawaguchi (Shiomidai Hospital), Akira Saito (Tokai University School of Medicine), Yoshiki Nishizawa (Osaka City University Graduate School of Medicine), Yusuke Tsukamoto (Shuwa General Hospital), Satoshi Kurihara (Tsukinomori Clinic), Takashi Akiba (Tokyo Women's Medical University), Eriko Kinugasa (Showa University Northern Yokohama Hospital), Yuzo Watanabe (Kasugai Municipal Hospital), Yoshihiro Tominaga (Nagoya Daini Red Cross Hospital), Takashi Shigematsu (Wakayama Medical University), Masaaki Inaba (Osaka City University Graduate School of Medicine), Jun Minakuchi (Kawashima Hospital), Hideki Hirakata (Fukuoka Red Cross Hospital), Keitaro Yokoyama (Jikei University School of Medicine), Naoki Kimata (Tokyo Women's Medical University), Fumihiko Koiwa (Showa University Fujigaoka Hospital), Ryoichi Ando (Musashino Red Cross Hospital), Junichiro J. Kazama (Niigata University), Takatoshi Kakuta (Tokai University School of Medicine), Daijo Inaguma (Nagoya Daini Red Cross Hospital), Eiji Ishimura (Osaka City University Graduate School of Medicine), Hideki Tahara (Osaka City University Graduate School of Medicine), Kazuhiko Tsuruya (Kyushu University), and Akira Fujimori (Konan Hospital).

\section{Disclosure Statement}

The MBD-5D is supported by research grants from Kyowa Hakko Kirin, without restrictions on publications. M.F. has acted as a consultant for Kyowa Hakko Kirin, has received honoraria from Kyowa Hakko Kirin, and has received grants/research support from Kyowa Hakko Kirin. H.K. has received honoraria from Kyowa Hakko Kirin. S.F. has acted as a scientific advisor for Kyowa Hakko Kirin, and has received grants/research support from Kyowa Hakko Kirin. T.A. has acted as a consultant for Kyowa Hakko Kirin, has received grants/research support from Kyowa Hakko Kirin, and is a member of speakers' bureau of Kyowa Hakko Kirin. K.K. and Y.O. have nothing to declare. 


\section{References}

-1 Jadoul M, Albert JM, Akiba T, Akizawa T, Arab L, Bragg-Gresham JL, Mason N, Prutz KG, Young EW, Pisoni RL: Incidence and risk factors for hip or other bone fractures among hemodialysis patients in the Dialysis Outcomes and Practice Patterns Study. Kidney Int 2006;70:1358-1366.

- 2 Danese MD, Kim J, Doan QV, Dylan M, Griffiths R, Chertow GM: PTH and the risks for hip, vertebral, and pelvic fractures among patients on dialysis. Am J Kidney Dis 2006; 47:149-156.

-3 Block GA, Klassen PS, Lazarus JM, Ofsthun N, Lowrie EG, Chertow GM: Mineral metabolism, mortality, and morbidity in maintenance hemodialysis. J Am Soc Nephrol 2004; 15:2208-2218.

-4 Kalantar-Zadeh K, Kuwae N, Regidor DL, Kovesdy CP, Kilpatrick RD, Shinaberger CS, McAllister CJ, Budoff MJ, Salusky IB, Kopple JD: Survival predictability of time-varying indicators of bone disease in maintenance hemodialysis patients. Kidney Int 2006;70: 771-780.

5 Tentori F, Blayney MJ, Albert JM, Gillespie BW, Kerr PG, Bommer J, Young EW, Akizawa T, Akiba T, Pisoni RL, Robinson BM, Port FK: Mortality risk for dialysis patients with different levels of serum calcium, phosphorus, and PTH: the Dialysis Outcomes and Practice Patterns Study (DOPPS). Am J Kidney Dis 2008;52:519-530.

6 Floege J, Kim J, Ireland E, Chazot C, Drueke T, de Francisco A, Kronenberg F, Marcelli D, Passlick-Deetjen J, Schernthaner G, Fouqueray B, Wheeler DC: Serum iPTH, calcium and phosphate, and the risk of mortality in a European hemodialysis population. Nephrol Dial Transplant (in press).

-7 Nakai S, Akiba T, Kazama J, Yokoyama K, Fukagawa M, Tominaga Y, Iseki K, Tsubakihara Y: Effects of serum levels of calcium, phosphorous, and intact parathyroid hormone levels on survival in chronic hemodialysis patients in Japan. Ther Apher Dial 2008; 12:49-54.

-8 Kimata N, Albert JM, Akiba T, Yamazaki S, Kawaguchi T, Fukuhara S, Akizawa T, Saito A, Asano Y, Kurokawa K, Pisoni RL, Port FK: Association of mineral metabolism factors with all-cause and cardiovascular mortality in hemodialysis patients: the Japan Dialysis Outcomes and Practice Patterns Study. Hemodial Int 2007;11:340-348.

$\checkmark 9$ Goodman WG, Goldin J, Kuizon BD, Yoon C, Gales B, Sider D, Wang Y, Chung J, Emerick A, Greaser L, Elashoff RM, Salusky IB: Coronary artery calcification in young adults with end-stage renal disease who are undergoing dialysis. N Engl J Med 2000;342: 1478-1483.
10 Raggi P, Boulay A, Chasan-Taber S, Amin N, Dillon M, Burke SK, Chertow GM: Cardiac calcification in adult hemodialysis patients. A link between end-stage renal disease and cardiovascular disease? J Am Coll Cardiol 2002;39:695-701.

11 National Kidney Foundation. K/DOQI clinical practice guidelines for bone metabolism and disease in chronic kidney disease. Am J Kidney Dis 2003;42(suppl 3):S1-S202.

12 Guideline Working Group, Japanese Society for Dialysis Therapy: Clinical practice guideline for the management of secondary hyperparathyroidism in chronic dialysis patients. Ther Apher Dial 2008;12:514-525.

13 Kidney Disease: Improving Global Outcomes (KDIGO) CKD-MBD Work Group: KDIGO clinical practice guideline for the diagnosis, evaluation, prevention, and treatment of Chronic Kidney Disease-Mineral and Bone Disorder (CKD-MBD). Kidney Int 2009;76(suppl 113):S1-S130.

14 Drüeke TB: Cell biology of parathyroid gland hyperplasia in chronic renal failure. J Am Soc Nephrol 2000;11:1141-1152.

15 Fukagawa M, Nakanishi S, Kazama JJ: Basic and clinical aspects of parathyroid hyperplasia in chronic kidney disease. Kidney Int 2006;70(suppl 102):S3-S7.

16 Palmer SC, McGregor DO, Macaskill P, Craig JC, Elder GJ, Strippoli GF: Meta-analysis: vitamin D compounds in chronic kidney disease. Ann Intern Med 2007;147:840853.

17 Fukuda N, Tanaka H, Tominaga Y, Fukagawa M, Kurokawa K, Seino Y: Decreased 1,25-dihydroxyvitamin $\mathrm{D}_{3}$ receptor density is associated with a more severe form of parathyroid hyperplasia in chronic uremic patients. J Clin Invest 1993;92:1436-1443.

18 Kifor O, Moore FD Jr, Wang P, Goldstein M, Vassilev P, Kifor I, Hebert SC, Brown EM: Reduced immunostaining for the extracellular $\mathrm{Ca}^{2+}$-sensing receptor in primary and uremic secondary hyperparathyroidism. J Clin Endocrinol Metab 1996;81: 1598-1606.

19 Gogusev J, Duchambon P, Hory B, Giovannini M, Goureau Y, Sarfati E, Drüeke TB: Depressed expression of calcium receptor in parathyroid gland tissue of patients with hyperparathyroidism. Kidney Int 1997;51:328336.

20 Fukagawa M, Kitaoka M, Yi H, Fukuda N, Matsumoto T, Ogata E, Kurokawa K: Serial evaluation of parathyroid size by ultrasonography is another useful marker for the long-term prognosis of calcitriol pulse therapy in chronic dialysis patient. Nephron 1994;68:221-228.
21 Okuno S, Ishimura E, Kitatani K, Chou H, Nagasue K, Maekawa K, Izumotani T, Yamakawa $\mathrm{T}$, Imanishi $\mathrm{Y}$, Shoji $\mathrm{T}$, Inaba $\mathrm{M}$, Nishizawa Y: Relationship between parathyroid gland size and responsiveness to maxacalcitol therapy in patients with secondary hyperparathyroidism. Nephrol Dial Transplant 2003;18:2613-2621.

-22 Tominaga Y, Inaguma D, Matsuoka S, Tahara H, Kukita K, Kurihara S, Onoda N, Tsuruta Y, Tsutsui S, Ohta K, Kuwahara M, Tanaka M, Nishizawa Y: Is the volume of the parathyroid gland a predictor of maxacalcitol response in advanced secondary hyperparathyroidism? Ther Apher Dial 2006;10: 198-204.

23 Tominaga Y, Numano M, Tanaka Y, Uchida K, Takagi H: Surgical treatment of renal hyperparathyroidism. Semin Surg Oncol 1997; 13:87-96.

24 Goodkin DA, Bragg-Gresham JL, Koenig KG, Wolfe RA, Akiba T, Andreucci VE, Saito A, Rayner HC, Kurokawa K, Port FK, Held PJ, Young EW: Association of comorbid conditions and mortality in hemodialysis patients in Europe, Japan, and the United States: the Dialysis Outcomes and Practice Patterns Study (DOPPS). J Am Soc Nephrol 2003; 10:3270-3277.

25 Fukagawa M, Yumita S, Akizawa T, Uchida E, Tsukamoto Y, Iwasaki M, Koshikawa S: Cinacalcet (KRN1493) effectively decreases the serum intact PTH level with favorable control of the serum phosphorus and calcium levels in Japanese dialysis patients. Nephrol Dial Transplant 2008;23:328-335.

26 Komaba H, Nakanishi S, Fujimori A, Tanaka M, Shin J, Shibuya K, Nishioka M, Hasegawa H, Kurosawa T, Fukagawa M: Cinacalcet effectively reduces parathyroid hormone secretion and gland volume regardless of pretreatment gland size in patients with secondary hyperparathyroidism. Clin J Am Soc Nephrol 2010;5:2305-2314.

27 Shigematsu T: Lanthanum carbonate effectively controls serum phosphate without affecting serum calcium levels in patients undergoing hemodialysis. Ther Apher Dial 2008; $12: 55-61$.

28 Goto S, Komaba H, Moriwaki K, Fujimori A, Shibuya K, Nishioka M, Kim JI, Yoshiya K, Shin J, Hasegawa H, Taniguchi M, Fujii H, Nishi S, Kamae I, Fukagawa M: Clinical efficacy and cost-effectiveness of lanthanum carbonate as second-line therapy in hemodialysis patients in Japan. Clin J Am Soc Nephrol (in press).

29 Fukuhara S, Akizawa T, Fukagawa M, Onishi Y, Yamaguchi T, Hasegawa T, Kurokawa $\mathrm{K}$ : Mineral and bone disorders outcomes study for Japanese chronic kidney disease stage $5 \mathrm{D}$ patients (MBD-5D): rationale and study design. Ther Apher Dial 2011;15:169175 . 
-30 Payne RB, Little AJ, Williams RB, Milner JR: Interpretation of serum calcium levels in patients with abnormal serum proteins. Br Med J 1973;4:643-646.

-31 Smogorzewski M, Zayed M, Zhang YB, Roe J, Massry SG: Parathyroid hormone increases cytosolic calcium concentration in adult rat cardiac myocytes. Am J Physiol 1993; 264:H1998-H2006.

>32 Amann K, Ritz E, Wiest G, Klaus G, Mall G: A role of parathyroid hormone for the activation of cardiac fibroblasts in uremia. J Am Soc Nephrol 1994;4:1814-1819.

- 33 Kestenbaum B, Andress DL, Schwartz SM, Gillen DL, Seliger SL, Jadav PR, Sherrard DJ, Stehman-Breen C: Survival following parathyroidectomy among United States dialysis patients. Kidney Int 2004;66:2010-2016.

-34 Hamano T, Oseto S, Fujii N, Ito T, Katayama M, Horio M, Imai E, Hori M: Impact of lowering dialysate calcium concentration on serum bone turnover markers in hemodialysis patients. Bone 2005;36:909-916.

-35 Shoji T, Shinohara K, Kimoto E, Emoto M, Tahara H, Koyama H, Inaba M, Fukumoto S, Ishimura E, Miki T, Tabata T, Nishizawa Y: Lower risk for cardiovascular mortality in oral $1 \alpha$-hydroxy-vitamin $\mathrm{D}_{3}$ users in a haemodialysis population. Nephrol Dial Transplant 2004;19:179-184.
36 Teng M, Wolf M, Ofsthun MN, Lazarus JM, Hernán MA, Camargo CA Jr, Thadhani R Activated injectable vitamin $\mathrm{D}$ and hemodialysis survival: a historical cohort study. J Am Soc Nephrol 2005;16:1115-1125.

37 Wolf M, Shah A, Gutierrez O, Ankers E, Monroy M, Tamez H, Steele D, Chang Y, Camargo CA Jr, Tonelli M, Thadhani R: Vitamin D levels and early mortality among incident hemodialysis patients. Kidney Int 2007;72:1004-1013.

38 Ureña P, Hruby M, Ferreira A, Ang KS, de Vernejoul MC: Plasma total versus bone alkaline phosphatase as markers of bone turnover in hemodialysis patients. J Am Soc Nephrol 1996;7:506-512.

39 Regidor DL, Kovesdy CP, Mehrotra R, Rambod M, Jing J, McAllister CJ, Van Wyck D, Kopple JD, Kalantar-Zadeh K: Serum alkaline phosphatase predicts mortality among maintenance hemodialysis patients. J Am Soc Nephrol 2008;19:2193-2203.

40 Blayney MJ, Pisoni RL, Bragg-Gresham JL, Bommer J, Piera L, Saito A, Akiba T, Keen ML, Young EW, Port FK: High alkaline phosphatase levels in hemodialysis patients are associated with higher risk of hospitalization and death. Kidney Int 2008;74:655663.
41 Shantouf R, Kovesdy CP, Kim Y, Ahmadi N, Luna A, Luna C, Rambod M, Nissenson AR, Budoff MJ, Kalantar-Zadeh K: Association of serum alkaline phosphatase with coronary artery calcification in maintenance hemodialysis patients. Clin J Am Soc Nephrol 2009;4:1106-1114.

42 Yokoyama K, Katoh N, Kubo H, Murai S, Imamura N, Shoji R, Yamamoto $\mathrm{H}$, Shigematsu T, Nakayama M, Takasu S, Kono T, Yoshida T, Hosoya T: Clinical significance of the K/DOQI bone guidelines in Japan. Am J Kidney Dis 2004;44:383-384.

43 Miller JE, Kovesdy CP, Norris KC, Mehrotra R, Nissenson AR, Kopple JD, Kalantar-Zadeh K: Association of cumulatively low or high serum calcium levels with mortality in long-term hemodialysis patients. Am J Nephrol 2010;32:403-413.

44 Cannata-Andía JB, Fernández-Martín JL, Zoccali C, London GM, Locatelli F, Ketteler M, Ferreira A, Covic A, Floege J, Górriz JL, Rutkowski B, Memmos DE, Verbeelen D, Tielemans C, Teplan V, Bos WJ, Nagy J, Kramar R, Goldsmith DJ, Martin PY, Wüthrich RP, Pavlovic D, Benedik M: Current Management of Secondary Hyperparathyroidism: a Multicenter Observational Study (COSMOS). J Nephrol 2008;3:290-298. 